\title{
Divine Interventions
}

\section{(Re)birth and Creation Narratives in} Fra mand til kvinder Lili Elbes bekendelser

\section{By SAbine Meyer}

Religiously connoted narratives consistently (re)appear in biographically aligned writing of and about male to female transsexuals. Alveady prominent in FRA MAND TIL KVINDE - an account from 1931 those narratives prove to establish, transport and reproduce power structures regarding the transsexual subject.

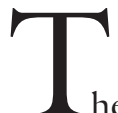

he transsexual biography: a testimony of the technical? natural? divine? The surgical intervention: a moment of transformation? birth? creation? The surgeon: a transformer? obstetrician? creator?

Biographical accounts of male to female transsexuals in particular, often seem to represent a peculiar interweaving of the parameters the introductory questions illustrate, culminating in what Sandy Stone terms "almost religious narratives of transformation" (Stone 2006: 222). Such narratives, found in numerous texts and forms, ${ }^{1}$ contribute to a disempowered voice of the transsexual subject by reproducing precast frameworks. At the same time those narratives empower the medical discourse through what I argue to be an elevation of the medical into the divine.

This is an apotheosis of Werner von Kreutz naturally (Elbe 1931: 1). ${ }^{2}$

So wrote Lili Elvenes - commonly known 
as Lili Elbe ${ }^{3}$ - in a letter to her friend Poul Knudsen summarizing the central aspect of a manuscript she was working on at the time. Werner von Kreutz was a pseudonym chosen for her surgeon Kurt Warnekros; the book manuscript - then to be titled "How Lili became a Real Girl" (Elbe 1931: 2) - was later to be incorporated into the book Fra Mand til Kvinde - Lili Elbes Bekendelser (From Man into Woman. Lili Elbe's Confessions), an influential, biographically inclined account first published in 1931.

Drawing on Stone, who touched on the interconnectivity of religious figurations and power structures, I will examine Fra Mand til Kvinde, a text permeated with religiously rooted narratives. By tracing those narratives throughout the text $\mathrm{I}$ intend to uncover how they inscribe power structures into the relationship between the medical subject and the transsexual subject.

Before delving into the analysis though, it is essential to take a closer look at the construction of genre and authorship in Fra Mand til Kvinde since those parameters are closely connected to the establishing of power structures inherent to the literary text.

\section{ThE CREATION OF CONFESSIONS}

While suggesting an autobiographical account, the book lacks a key paratextual element - the specification of an author. It has but a title: Fra Mand til Kvinde, and a subtitle: Lili Elbes Bekendelser. Neither authorship by Lili Elbe nor editorship by Niels Hoyer is paratextually clearly specified. 4 Employing Phillippe Lejeune's theories this constitutes a violation of the autobiographical pact, but Lejeune leaves a backdoor open in his remarks regarding the anonymous author (Lejeune 1994: 30-38) that enables Fra Mand til Kvinde still to qualify as an autobiography and Elbe as an author.

As soon as the narration begins however, said backdoor is quickly closing: an external narrator zooms in on the fictitiously renamed protagonist Andreas Sparre (Einar Wegener), ${ }^{5}$ his wife Grete (Gerda Wegener) as well as a friendly couple on the very night before Andreas is to meet the German gynaecologist Werner Kreutz (Kurt Warnekros). The point of view in the opening scene now disqualifies Fra Mand to Kvinde from being an autobiography, but suggests a classification as biography (Lejeune 1994: 42-45).

After Kreutz' diagnosis and his promise to help Andreas as well as giving him or respectively Lili a "new life and a new youth" (Fra Mand til Kvinde (FMTK) 1931: 17), the narration continues with a Berlinbound Andreas as first-person narrator. Despite the alleged incongruity between Andreas Sparre and the presumed author Lili Elbe, this changed point of view would now also disqualify a biographical classification. Engaging different narrators as well as different points of view, Fra Mand til Kvinde initially presents itself as a hybrid text oscillating between biography and autobiography. Yet, the problems of classification are only just beginning.

Feeling uncomfortable after an encounter with Prof. Hardenfeld (Magnus Hirschfeld) Andreas spends his first night in Berlin - and last night as Andreas - recapturing his life as well as Lili's, while his friend Niels Hvide (Poul Knudsen) takes notes of Andreas' retrospective tale. This is only one example of a keen employment of narrative techniques which, as Dag Heede pointed out, create a highly literalized as well as stylized (Heede 2003: 21) - and I may add fictionalized - text, which consequently leads to the questioning of an (auto)biographical classification altogether. Fra Mand til Kvinde seems to drift in a grey zone, for according to Lejeune it cannot qualify as a novel either (Lejeune 1994: 30-38).

As Lejeune's tools do not prove helpful in terms of actually distinguishing a genre for the text, the possibility of it being one 
of those medical accounts disguised as literature that were popular in contemporary sexology seems to suggest itself. Yet, the text also disproves this suggestion. When we are told that the first operation, conducted by Dr. Gebhard (Erwin Gohrbandt), eliminates Andreas from the previously shared body and leaves only Lili behind, the character of the surgical intervention performed is not disclosed to us. ${ }^{6}$ The reader is left equally in the dark about the following two procedures performed by Werner Kreutz at the Frauenklinik in Dresden ${ }^{7}$ but learns much about how well Lili responds to the treatments and how she ultimately feels at home in Dresden and wishes to remain there. Medical information is evidently withheld to give more space to a less technical narrative of Lili's transformation.

After returning to Copenhagen and tentatively turning down a marriage proposal from an old friend Lili returns to Dresden wanting to be able to have children. At this point the cohesive narration abruptly ends and the book continues with fragments from letters Lili presumably wrote during the three terminal months between her final - and again mysterious - surgery and her death in September 1931.8 The concluding statement provides the only definite medical information, informing the reader that, according to her medical papers, Lili died of a heart spasm caused by a long-term kidney disease.

While it is very likely that her death was a long-term effect of the terminal surgery, this final statement absolves Werner Kreutz and consequently also Kurt Warnekros9 from responsibility for Lili's death. If and how Warnekros influenced that last statement is difficult to reconstruct; 10 it does however raise an essential question already implied in the previously mentioned missing paratextual element - who are the authorial figures behind Fra Mand til Kvinde? The answer is closely connected to the problematic determination of genre classifi- cation. With its diverse narrative structures, Fra Mand til Kvinde presents itself as something I wish to call a fictionalized biographical collage, and I argue that the authorial structures behind it are equally collage-like.

Technically, the book is a collaboration of six individuals and a publishing house: Lili Elvenes, Gerda Wegener and Poul Knudsen - a friend of theirs - supplied the records they had kept; initially those records were assembled by the journalist Loulou Lassen, a task that was resumed by Ernst Hathern who under the pseudonym Niels Hoyer turned the records into a German manuscript; the manuscript was proofread by Kurt Warnekros and eventually translated into Danish and edited at Hage \& Clausens Forlag. An essential aspect in this technicality is the allocation of the last and thus defining word on Fra Mand til Kvinde, which can be determined by addressing the order in which the assumed original word is funnelled through the collaboration process. Whilst I would argue that a publishing institution per definition has the superordinate say on the final published word, in the case of Fra Mand til Kvinde, it is a medical authority that concludes the preceding collaboration process and also authorizes the book, as confirmed in the introductory text by Niels Hoyer. By approving the book and having that approval included into the preface, Warnekros acts as an editorial authority as well as a form of paratextual bailsman, especially considering the absence of a clearly specified authorial figure.

Both the hybrid text form and the hierarchised writing collaboration interweave with the key narratives of the book, which derive their impact through a continuous interchange of both narrator and narration as well as through the predominant polarised relationship between Lili Elvenes and Kurt Warnekros on an extratextual level, respectively Lili Elbe and Werner Kreutz on an intratextual level. 


\section{A RECURRING DREAM OF RELIGIOUS EN-GENDERING}

Fra Mand til Kvinde's core theme of exhibiting the extraordinary while abiding the normative is augmented in two closely linked key narratives - one being the unconditional perpetuation of a heteronormative matrix, the other being a religious elevation of Lili's surgical transformation as well as of her surgeon Werner Kreutz.

The former is emphasized by Stone who, while stressing the sexual repression of the historical period, points out the "description of 'woman' as male fetish, as replicating a socially enforced role, or as constituted by performative gender." (Stone 2006: 225) The performative notion is picked up by Heede who reads Fra Mand til Kvinde as the constituent force that creates 'woman' and acts "as a form of 'evidence' for Lili's femininity" (Heede 2003: 17-18). Stone's and Heede's readings underline the text's key function of verifying both Andreas Sparre's heterosexual masculinity as well as Lili Elbe's heterosexual femininity. Stone depicts the lack of ambiguous gender identification and in-between territory, and argues that to maintain the dichotomous structure, a specific narrative moment, when the personal sexual identification changes from male to female, is constructed - the moment of gender reassignment surgery. While Fra Man til Kvinde offers a specific narrative moment when Andreas disappears and only Lili remains, the identification change from male to female is allocated to several surgical as well as transcendental interventions during which "Lili displaces the irruptive masculine self, still dangerously present within her, onto the Godfigure of her surgeon/therapist Werner Kreutz" (Stone 2006: 225). Here, Stone already suggests the interweaving of the two key narratives and illustrates how Lili's gendered dependencies on Kreutz translate into the religiously connoted narrative.

The interweaving of both narratives becomes apparent in a prophesying dream
Andreas has before leaving Paris for Berlin. This dream will be the basis for my argumentation since it is a central lynchpin for (re)birth and creation motifs and recurs throughout the book. It symbolizes the past struggle of two oppositely gendered individuals living in the same body, headed for death, as opposed to the notion that only one of them can survive by leaving the original body and being reborn - through a present, religiously connoted journey of rebirth:

He [Andreas] sat in the train to Berlin ...... it sped through Northern France ..... the speed was so high, the train hardly had any side motion - it was as if it was unresisting and sinking into the distance. Andreas sat by the window and stared out over the woods and fields, when suddenly in the mist he saw a supernaturally tall, pitch black horseman who raced with the speeding train - he rode so fast his cape paralleled the wind, tightened like a sail. ..... the train did not stop at the stations any longer, it just sped on ...... but each time it rushed past a station, Andreas still perceived the unsettling, black horseman in the flickering light of the platform lamps ...... bit by bit the dark shifted character, as if the train sped through areas that never knew sunlight ...... and suddenly all passengers crowded themselves through the corridors towards the locomotive to help the fireman; they shovelled coal into the glowing machine to increase the speed, and Andreas understood that the horseman next to the train was Death ...... the horseman constantly struck out his arm, grabbed a passenger and broke him between his nails with gruesome laughter ...... In its insane speed the train lost coach after coach - eventually only the tender behind the locomotive was left ...... they reached the end of the world and the train fell into never ending depths ......

But Andreas had jumped off and is now on a small path which is sharp as a knife blade and bathed in light. And suddenly Lili appears by his side. He grabs her hand and they 
run along the razor-sharp path, hunted by Death who by now no longer rides his horse ...... But Lili's strength perishes, and Death constantly comes closer ...... so Andreas shouts: "Run little sister, run ...... I will fight Death for you" ...... the battle does not last long, Death, being stronger, grabs Andreas, lifts him up, sucks the life out of him and throws him into the abyss where his body twirls round and round like a faded leaf ...... But Lili runs and runs, until she reaches the end of the narrow path. And she jumps off and falls into the arms of a figure dressed in white. Death reaches out for her with its hands, but the white figure grows and becomes big and powerful, unfolds its white wings and fills the entire space ..... inch by inch it repels Death ...... And now, Lili is on an island with shining silver birches ...... quivering she has fallen on her knees, and a small, pale red gothic angel is holding her up while she hears the booming of the gigantic wings when Death is overcome by the fighting genius and disappears in the depth ...... (FMTK 1931: 21-22).

This dream sequence not only contains traces of the two narratives, but also functions as an initial point in composing a moment of suspense that is to be gradually resolved in the course of the narration. Andreas and Lili appear in the clearly binary gendered figuration of brother and sister, which accentuates the reproduction of normative stereotypes when a male Andreas, as Heede calls it, "strongly and chivalrously" (Heede 2003: 26) sacrifices himself for a weak female Lili. Deprived of Andreas now, Lili needs to reassign her male gendered self-responsibility and does so, as already denoted by Stone, not by taking it on herself, but by displacing it onto the mysterious redemptive figure - later to be equalised with Werner Kreutz. The dream already anticipates the resolution of the suspense surrounding said figure by dressing it as a white antidote to the black horseman and therefore not only imbuing it with reli- gious connotations, but medical connotations too.

The sequence is first picked up when Andreas, reconnecting with the first part of the dream, remembers the black horseman on his actual train journey to Berlin. Having planned suicide previous to meeting Kreutz, he is now escaping from death and on the way to literally jumping off that train in Berlin and figuratively stepping onto the narrow, razor-sharp birthing path, setting Lili's delivery into motion.

\section{TO BE BORN FULLY CONSCIOUS \\ THROUGH ONE'S OWN PANGS}

Towards the end of Fra Mand til Kvinde, Lili is said to be summarizing her confessions as the story "of the first person that was not born unconsciously through a mother's travail, but fully conscious through her own pangs" (FMTK 1931: 177). Those pangs had eliminated Andreas Sparre and created or rather recreated Lili the girl that had previously served as an almost childlike companion in Andreas' and Grete's marriage. As a form of surrogate mother, that very Lili is giving birth to her newborn self earlier in the book.

After the first surgery in Berlin, a confused childlike individual wakes up asking the inevitable questions: "Who am I? ..... What am I?" (FMTK 1931: 81). While still being referred to as Andreas, Lili cannot begin to officially exist without external approval. Her new femininity needs to be mirrored to her by her surroundings for she, now repeatedly being referred to as a child, surrenders her speaking position. In a highly staged manner, a friend alerts Andreas to his changed handwriting, which he cannot recognize - "it was a woman's script" (ibid.: 82). The change is then confirmed by a medical assistant who also comments on a shift in the voice - "[i]t is no longer a man's voice" (ibid.: 83). The performative assignation of gendered change in script and voice, thus the means of literal 
expression, accompanies a descent into a female speaking position. It also functions as an authorized set-up for the upcoming symbolical doubling of Andreas' death and Lili's birth. Hearing screams from an adjoining room, assuming that someone is dying, Andreas learns that to the contrary a young woman just gave birth to "a charming little girl" (ibid.: 83), and sobbingly realizes as well as exclaims: "Yes, yes, so I have to give birth to myself!" (ibid.: 84). Only after this process, Lili is recognized as Lili by those around her as well as the text.

While she is acknowledged as female, she is not seen as a woman. This becomes especially apparent in Grete's words: "She is so womanly and untouched by life ..... no, womanly is not the right word, I would rather call it young girlish, almost childlike, timid and insecure, with a thousand questions on her lips ....." (FMTK 1931: 86). Picked up in different points of view, this notion of Lili as a child is closely linked to a degendering of her persona. Pictured as minor and immature, she cannot voice herself and accordingly develops the wish to completely subordinate to others - a theme later to be incorporated into the narrative construction of her femininity. Her (de)gendered status is consequently mirrored by those around her and summarized by Grete who remarks how nobody can be sure, "whether they should regard that suffering creature as a man, or whether they should already speak to her as to a woman." (ibid.: 87)

Equally confused yet recuperating, Lili adapts to those doubts realizing she has not yet reached the end of that narrow, razorsharp birthing path she is on. Panicking again in a childlike manner - she only sees "a sad, tired, bloodless nymph" (FMTK 1931: 99) when looking into the mirror. Finding Lili like that, Grete nourishes both the child theme as well as the rebirth notion by telling Lili that she "resemble[s] a little, sweet mother that worries about her child" (ibid.: 99). Though mother and child at the same time, Lili is unable to pass through that transformation period on her own. An understanding between her and Grete anticipates Werner Kreutz as the only one being able to hatch the childlike nymph that so far is neither man nor woman.

\section{THE LORD AND MASTER}

From the very first meeting between Andreas Sparre and Werner Kreutz, Kreutz is described as a person radiating a peculiar power. His voice is intoxicating and calls for obedience, his eyes have a strange beguiling power - both "that gaze and voice penetrated deep into his [Andreas'] soul" (FMTK 1931: 16). Then, on departing from that meeting, Andreas looks back up to the window where Kreutz had positioned himself - the professor's profile is sharply sketched between the clouds and the sunlight. The repeated use of such images throughout the text clearly predestines Kreutz as a transcendental creator.

Arriving in Dresden, Lili impatiently awaits help from Kreutz - to whom she from now on subordinates her life. Recounting the set back a girlish Lili feels after learning about her delayed admission to the Frauenklinik, the external narrator illustrates how for the first time "her woman's heart had trembled before a lord and master" (FMTK 1931: 109). The initially announced apotheosis of Kreutz is now distinctly verbalized and followed up by a diary entry of Grete that ascribes him with the supernatural power of creating life and womanhood, even before performing any surgery on Lili:

Hitherto Lili has been like a lump of clay, others have worked with, and which the professor himself with just a swift touch has already given life ...... and form ...... but until now, he reckons, Lili's femininity lies on the surface only ...... it is not quite genuine yet since it hasn't infiltrated into depth ...... with 
just one look he awoke her heart to life yesterday - a life ensouled with all female instincts ...... (FMTK 1931: 110).

The obvious religious connotation of man being created from clay implies the divine touch of Kreutz as opposed to the fleshly touch of his predecessors who left 'monstrous freaks' like those Andreas met in the institute of Hardenfeld or 'unfinished nymphs' like Lili herself. In her case, only a divine figure like Kreutz could create a gendered human being and elevate her into "something that was more meaningful and more powerful than anything else, something that raised itself high above all other human destinies" (FMTK 1931: 112). Stone not only shows that this transcendental narration establishes Kreutz as Lili's divine moulder, but also denotes the transsexual body as "inscribed with the 'true' story of Adam and Eve" (Stone 2006: 230). In divine manner, Kreutz is going to cut 'woman' out of a body previously perceived as male when Lili - still walking the razor-sharp path - steps under the knife, gently led by the master himself. At the same time, Grete waits outside contemplating Kreutz' power and - as she later recaptures in her diaries - understands that she, among many others, is just a believer, believing in his superior almightiness:

What kind of strange power was that which he was radiating? Here in the women's clinic, he was a God everyone feared and worshipped. [...] And I understood that I was only one of the many believers, that I believed in that man, believed in him as the one that had the capacity and was able to do everything, as the one, who had it in his power to help (FMTK 1931: 119).

The temporal intersection of Grete's declaration of faith and the surgery performed on Lili constitutes an apotheotic moment that turns the surgical intervention into a divine intervention of creation. Lili conse- quently declares her faith in Kreutz as well and calls that very day the day of "her actual birth" (FMTK 1931: 122) while recuperating in the Frauenklinik with its garden full of shining silver birches. "Her white hospitalized existence seemed like paradise to her, and the professor was the guardian of that paradise" (ibid.: 123). In the wake of that notion Lili remembers the initial dream again - "the white figure, that stood between her and Death, and the lucid birch copse out there in the universe" (ibid.: 126) - and hence denotes the correspondence between the religiously connoted dream and the events in Dresden.

Living the transcendental moment of the dream sequence, Lili is unable to imagine a life outside of her paradise. Fearing the moment of complete recovery, she can only imagine either becoming a nun or serving her figurative god Werner Kreutz and being a nurse at the Frauenklinik. Subordination and obsessive gratitude accompany Lili's every step after she declares: "My life is his creation" (FMTK 1931: 128). Having soon recuperated from a second operation, Lili is advised by Kreutz to leave Dresden. Wanting to stay, she feels thrown out of the nest, but obeys Kreutz' calling, trying to live her young girl life - a life that has but one purpose - being a woman her creator would be proud of, being the woman, she thinks, he created her to be: "I had to be beautiful; if I did not look good, I had lost any right to exist, to be woman ...... for then, I would no longer do him, who had created me, Professor Werner Kreutz, credit" (ibid.: 149). Here the text takes us back to Stone's remarks on 'woman' as male fetish and her corresponding questions: "Not by whom but for whom was Lili Elbe constructed? Under whose gaze did her text fall?" (Stone 2006: 224). While the answers are obvious, Heede goes as far as arguing that not only does the text fall under a male gaze, but that 'it is Kreutz' gaze that acts as the crucial generator in the production of Lili's 
womanhood not the operation" (Heede 2003: 34). His clinic is not simply a paradise, but "a patriarchal paradise" (ibid.: $35)$.

Throughout her time outside of Dresden, Lili continuously wishes to go back to the paradise garden of her girlhood. Feeling that she owes her life to Kreutz, she believes herself to be unconditionally dependent on his guidance and finds it impossible to make decisions about her own life. When an old friend asks for her hand in marriage, she tentatively declines. Stating that she is too young to be entitled to take such a decision, she informs her suitor: "Without his permission, I cannot do anything at all ..... he has sole custody of me. [...] Him I have to consult ..... It is he who has to decide what shall become of me and to show me the way I have to go" (FMTK 1931: 172-173).

Longing for the garden full of birches, now explicitly equated with the Garden of Eden, Lili returns to Dresden. On her journey, the initial dream, "the only recollection of Andreas' time that was sharply sketched in her memory" (FMTK 1931: 176) reappears one last time. Lili now connects the persona of Kreutz with the white figure rescuing her in the dream sequence the figure that showed her the way towards the end of the path.

\section{ELEVATING THE MEDICAL INTO}

\section{THE DIVINE}

What Stone calls the "mysterious power of the Man-God" (Stone 2006: 226) is a recurring element, transforming many male to female biographical accounts into stencils operating with the same two key narratives over and over again. They do however become especially apparent in Fra Mand til Kvinde, a text that holds a particular significance.

As already indicated, the religiously motivated narrative of (re)birth and creation corresponds with the male-female dichoto- my with which the heteronormative narrative operates. It translates the core structures of that dichotomy into a surgeon-patient, creator-creation as well as parentchild level. I argue that images of birth and rebirth serve as indicators for the various stages of Lili's transition and leave her in a childlike state. She is muzzled and dependent on her surroundings, especially reliant on Kreutz who figuratively as well as literally is turned into a god-like persona. $\mathrm{He}$ is the only one endowed with the divine power of making the transsexual nymph that is Lili, hatch into a normative woman. That power is not only surgical, but also procreational, sexual and transcendental. Kreutz is surgeon, father, man and creator to Lili Elbe - his patient, child, woman and creation.

Fra Mand til Kvinde not only set an example on a literary level, but also advised readers about the competences regarding transsexuality. The collage-like structure of the book allows mutual authorizing through interchanging points of view. The defining word is assigned to Werner Kreutz respectively Kurt Warnekros - introducing medical authority not only through the preface but also through the authorial collaboration process. Though medical science is not positively depicted as a whole, ${ }^{11}$ it is highlighted as the space that harbours help and miracles, the space in which to look for an almighty surgeon holding all the answers.

The superordinate extratextual interventions as well as the divine intratextual interventions connected to Fra Mand til Kvinde are clearly medical, and therefore not only illustrate the reception of a singular transmedical relationship, but demonstrate power structures on a larger scale. By elevating the medical into the divine, they help - at that time - to place the medical discourse at the top of the hierarchy of discourses on transsexuality. 


\section{Notes}

1. See e.g. Morris (1974) or Nimb (2001).

2. All translations from Danish to English are mine.

3. After undergoing sex reassigning surgeries in

Dresden Einar Wegener's name was officially changed into Lili Ilse Elvenes in December 1930.

(Kirkebog 1881-1891 Vejle Sct Nicolai); considering that it almost only appears in sources connected to Fra Mand til Kvinde, it is very likely that 'Elbe' was a pseudonymous name created to support a literary narrative.

4. Unlike the Danish edition, the altered German edition indicates Lili Elbe as the author while both the German and the English edition indicate Niels Hoyer as the editor of the book.

5. A brief introductory text by Niels Hoyer states that fictitious names are employed at Elbe's desire and only her own name is retained. I will disclose the names of the persons the key characters in the book are modelled on once and further use the fictitious names when referring to Fra Mand til Kvinde.

6. The German edition contains a letter informing the reader that this first intervention was a castration.

7. Again Fra Mand til Kvinde does not disclose what the two operations entailed. It suggests the implantation of gonads for the second intervention while the German edition discloses the second operation as the amputation of the penis, the third as the implantation of ovaries.

8. A number of these letters are accessible and show that significant changes have been made from the original letter to the reprinted fragments in the book.

9. At the time of Fra Mand til Kvinde's release, the reader was well informed about Kurt Warnekros, courtesy of several newspapers. The fictitious name hence did not grant anonymity. 10. All medical papers were destroyed during the air raid on Dresden in February 1945, and as far as I have been able to determine, only Warnekros' notes on the final version of the manuscript are accessible. Said manuscript neither includes the information about the cause of Lili Elbe's death nor any handwritten remarks suggesting a change in that direction.

11. Andreas' first medical encounters in Paris are described as thoroughly negative experiences. Furthermore a rivalry between Hardenfeld and Kreutz is implied in the text. Hardenfeld as well as his institute are not depicted as entirely positive.

\section{LITERATURE}

- Fra Mand til Kvinde. Lili Elbe's Bekendelser (1931). Hage \& Clausens Forlag, København. Elbe, Lili (1931): Letter to Poul Knudsen, 31 January 1931. Copenhagen: The Royal Library: Department of Manuscripts and Rare Books: Collection NKS $2692.2^{\circ}$.I.2.

· Heede, Dag (2003): "At gøre kvinde. Lili Elbe: Fra Mand til Kvinde", i: Handicaphistorisk tidsskrift, 2003/9.

- Lejeune, Philippe (1994) [1975]: Der autobiographische Pakt. Wolfram Bayer \& Dieter Hornig (tr.), Suhrkamp, Frankfurt am Main.

- Morris, Jan (2002) [1974]: Conundrum, Faber and Faber, London.

- Nimb, Bente (2001): Rejsen mod Bente - Konsskifteoperationen i Casablanca. Borgen, København.

. Stone, Sandy (2006): “The Empire Strikes Back. A Posttranssexual Manifesto" [1987], in: Susan Stryker \& Stephen Whittle (eds.): The Transsexual Studies Reader, Routledge, New York.

\section{SUMMARY}

Divine interventions. (Re)birth and creation narratives in Fra mand til kvinde - Lili Elbes bekendelser

With (re)birth and creation narratives being a prominent strand in biographically aligned writing especially of and about male to female transsexuals, looking at an early account like Fra Mand til Kvinde (1931) elucidates how the bierarchy between medicine and transsexual subject is inscribed into such texts. The article examines how (re)birth narratives serve as indicators for the various stages of Lili Elbe's transition while leaving her in a subordinate state and dependent on the moulding of her surroundings, especially her surgeon who is staged as a god-like persona and hence appears as the creating force behind Elbe's transformation. Engaging with those allegedly 'divine interventions', not only highlights the reception of a trans-medical relationship but also exposes the reproduction of power structures on a larger scale.

Sabine Meyer, Ph.D. student Department for Northern European Studies Humboldt Universität, Berlin 